DOI: http://dx.doi.org/10.18764/2358-4319.v12n1p272-296

\title{
Consolidação da formação dos professores de Ciências Naturais na Região Araguaia/Xingu (1980 - 2016)
}

\author{
Danilo Fernando Luz Oliveira' \\ Ana Claudia Tasinaffo Alves ${ }^{2}$ \\ Marcelo Franco Leão ${ }^{3}$
}

\section{RESUMO}

Esse estudo teve como objetivo descrever e analisar o processo de formação dos professores de ciências naturais na região Araguaia/Xingu, desde a década de 80 a atualidade. Foram investigados o projeto Inajá, o programa Parceladas da UNEMAT e as licenciaturas e especialização em Ensino de Ciências do IFMT Campus Confresa. De natureza básica, o estudo é descritivo e exploratório, de abordagem qualitativa e caracteriza-se como uma pesquisa documental. Inicialmente, os leigos lutam por sua formação e a conseguem com o curso de magistério do Projeto Inajá. A UNEMAT implanta na cidade de Luciara o Campus Médio do Araguaia com a oferta de Licenciaturas Parceladas com habilitação específica em ciências. Também são apresentados avanços proporcionados pelo IFMT para a formação inicial e continuada de professores de ciências na região, presencial e a distância. Logo, esses avanços para formação específica na área certamente favoreceram o ensino de ciências naturais nas escolas da região.

Palavras-chave: Formação de professores. Ensino de ciências. Retrospecto histórico.

1 Especialista em Ensino de Ciências. Professor de Ciências da Natureza na Educação Básica Escola Estadual Creuslhi de Souza Ramos - Escola Plena. Coordenador Pedagógico no Centro de Educação de Jovens e Adultos (CEJA).E-mail: dfluz_oliveira@hotmail.com

2 Doutora em Educação Ciências e Matemática (REAMEC/UFMT). Pofessora do Instituto Federal de Educação, Ciência e Tecnologia de Mato Grosso - IFMT Campus Confresa/MT. Membro do Grupo de Pesquisa Ensino de Ciências e Matemática no Baixo Araguaia (EnCiMa) e do Grupo de Pesquisa Laboratório de Pesquisa e Ensino de Química de Mato Grosso (LabPEQ-UFMT). E-mail: ana.alves@cfs.ifmt.edu.br

3 Doutor em Educação e Ensino de Ciências pela Universidade Federal do Rio Grande do Sul (UFRGS). Professor do Instituto Federal de Educação, Ciência e Tecnologia do Mato Grosso (IFMT), Campus de Confresa/MT. Participa do Grupo de Pesquisa Ensino de Ciências e Matemática no Baixo Araguaia (EnCiMa). Editor da Revista Prática Docente. E-mail: marcelo. leao@cfs.ifmt.edu.br 


\title{
Consolidation of the formation of teachers of Natural Sciences in the Araguaia/Xingu Region (1980 - 2016)
}

\begin{abstract}
The objective of this study is to describe and analyze the natural sciences teacher formation in the Araguaia/Xingu region from the 1980s to the present. It investigated the Inajá project, the UNEMAT staggered program and the licentiate degrees and specialization in Sciences Teaching at the IFMT Confresa Campus. The study is of a basic nature and is descriptive and exploratory from a qualitative approach and is characterized as a document research. Initially, lay people struggle for their formation and obtain it through the Projeto Inajá mastership. UNEMAT has implemented in the city of Luciara the Médio do Araguaia Campus and offers Staggered Licentiate Degrees with specific qualification in sciences. It also presents advancements made possible by the IFMT for early and continuous sciences teacher formation in the region, both presential and distance. Thus, such advancements for specific training in the area will most certainly favor the teaching of natural sciences in the region.
\end{abstract}

Keywords: Teacher training. Sciences teaching. Historical hindsight.

\section{Consolidación de la formación de los profesores de Ciencias Naturales en la Región Araguaia/Xingu (1980 - 2016)}

\section{RESUMEN}

Este estudio tuvo como objetivo describir y analizar el proceso de formación de los profesores de ciencias naturales en la región Araguaia / Xingu, de la década de 80 para acá. Se investigó el proyecto Inajá, el programa Parceladas de UNEMAT y las licenciaturas y especialización en Enseñanza de Ciencias del IFMT Campus Confresa. De carácter básico, el estudio es descriptivo y exploratorio, de abordaje cualitativo y se caracteriza como una investigación documental. Inicialmente, los laicos luchan por su formación y la logran con el curso de magisterio del Proyecto Inajá. La UNEMAT implanta en la ciudad de Luciara el Campus Medio del Araguaia con la oferta de Licenciaturas Parceladas con habilitación específica en ciencias. También se presentan avances proporcionados por el IFMT para la formación inicial y continuada de profesores de ciencias en la región, presencial ya distancia. Por lo tanto, estos avances para 
formación específica en el área ciertamente favorecieron la enseñanza de ciencias naturales en las escuelas de la región.

Palabras-clave: Formación de profesores. Enseñanza de ciencias. Retrospectiva histórica

\section{Introdução}

Registrar e discutir sobre a formação de professores de ciências naturais na região Araguaia/Xingu, além de permitir conhecer o contexto histórico em que se estabeleceram, ajudará na compreensão e na consolidação desse processo formativo. Além disso, a temática ainda carece de estudos e aprimoramento. Se a formação de professores foi tardia nas regiões sul e sudeste do país, no interior do Mato Grosso foi ainda mais. Isso fez com que pessoas sem formação específica assumissem as aulas de ciências naturais para suprir uma necessidade, todavia essas ações têm reflexos na qualidade do ensino até os dias atuais (OLIVEIRA; ALVES; LEÃO, 2016).

Discutir sobre a formação recebida pelos professores da área torna-se quase como uma necessidade, pois refletir como ocorreu o processo pode vir a influenciar os atuais e futuros professores da área. Nessa linha de pensamento, Freitas e Villani (2002, p. 215), afirmam que "a formação dos professores de ciências, geralmente, tem sido pensada como uma tentativa de produzir um profissional que incorpore, o máximo possível, traços ideais selecionados a partir de uma reflexão teórica sobre o tema".

Segundo Ayres e Selles (2012), o processo formativo de professores no Brasil teve início em 1930, mesmo já tendo sido organizado o ensino secundário em 1837 com a fundação do Colégio Pedro II. Pensar primeiro a organização do ensino secundário e só depois discutir o processo formativo de professores no Brasil foi uma estratégia que culminou em resultados negativos na formação de docentes. Esse descompasso se reflete principalmente na formação de professores de ciências. Malucelli (2007, p. 114), aponta que esses sujeitos carecem de uma formação adequada, e não são conscientes de suas insuficiências.

O apontamento de Malucelli (2007) se confirma nos argumentos de Carvalho e Gil-Pérez (1995, p. 14), pois, nós professores de ciências, não só carecemos de uma formação adequada como não somos sequer conscientes de nossas insuficiências. Como consequência, concebe-se a formação do professor como uma transmissão de conhecimentos e destrezas. 
Ayres e Selles (2012, p. 99), apontam que a trajetória da formação docente voltada ao ensino de Ciências no nível fundamental configura-se como um caso peculiar que precisa ser compreendida na sua articulação. A formação de professores de ciências foi pensada e articulada em vários formatos e não levou em consideração o "sujeito professor" que estaria no "seio" da sala de aula todos os dias.

Todavia, no ano de 1965 surge o curso de Licenciatura de $1^{\circ}$ ciclo, ou Licenciatura Curta em Ciências [...], que segundo as autoras (idem, p. 97) tinha o objetivo de formar professores para lecionar tanto Ciências quanto Matemática no curso ginasial, constituindo-se em uma proposta de formar um professor "polivalente", isto é, habilitado nas duas disciplinas mencionadas. As Licenciaturas curtas, (idem, p. 101), foram pensadas e articuladas no sentido de atender a especificidade do ensino de Ciências, pois a licenciatura em Ciências Biológicas, em 1963, não conseguia.

Essa vertente mostra que a formação em "massa" de professores e principalmente os de ciências, por meio de programas, não condiz com a realidade vivida, pois está separada da realidade cultural, social e política, e não consegue fazer com que o professor de ciências, ao terminar o curso universitário, lide adequadamente com as especificidades da ação docente em sala de aula (MOURA, 2006, p. 46).

Barolli e Villani (2015, p. 76), justificam que:

\begin{abstract}
A formação de professores de ciências, ao longo desses últimos 50 anos, pode ser pensada como campo, já que esse conceito nos permite traçar algumas semelhanças que nos auxiliam a explicitar a dinâmica das orientações que o ensino de ciências vem recebendo ao longo de sua história.
\end{abstract}

Nessa análise, Moura (2006, p. 47) afirma que "a universidade forma para o exercício docente sem saber ao certo o que a escola precisa, quais seus anseios, que dúvidas têm o professor de ciências e qual a realidade da sala de aula", já Carvalho e Gil-Pérez (2001, p.120), explicitam que "um profissional, para ser professor, precisa dominar os saberes pedagógicos".

Diante do exposto, o objetivo desse estudo é narrar e analisar o processo de formação dos professores de ciências da região Araguaia/ Xingu, a partir da década de 1980, tendo como foco o projeto Inajá, o programa Parceladas da Universidade do Estado de Mato Grosso (UNEMAT) e as graduações em ciências da natureza com habilitação em Quí- 
mica, Física e Biologia do Instituto Federal de Educação, Ciência e Tecnologia de Mato Grosso (IFMT) Campus Confresa.

A emigração para a região Araguaia/Xingu começou após a década de 1950, tanto espontaneamente como por políticas de colonização oficiais. Mas os primeiros cursos de formação de professores de ciências se iniciaram apenas na década de 1980 na referida região. Sendo que o munícipio mais antigo da região, São Félix do Araguaia, foi fundado em 1976.

Para alcançar o objetivo proposto, utilizou-se o método de pesquisa qualitativa, com características de natureza básica e procedimentos da pesquisa bibliográfica e documental. Nos resultados, seguiu-se uma linha cronológica de acontecimentos, pois o processo de formação dos professores de ciências da região Araguaia/Xingu ocorreu em diferentes períodos (1980 - 2016), e lugares e com diferentes sujeitos.

Para melhor organizar a apresentação desse estudo, seguem quatro seções, sendo a primeira com a caracterização da região Araguaia/Xingu, sua localização, bem como as diferentes nomenclaturas que lhe foram atribuídas. A segunda aborda como o trabalho foi formulado e os procedimentos utilizados para alcançar o objetivo da pesquisa. Na terceira, são apresentados os resultados na forma de três tópicos, cujo primeiro discute-se a formação oferecida aos professores leigos por meio do Projeto Inajá, o segundo refere-se aos cursos de licenciatura na modalidade Parceladas da UNEMAT e o terceiro sobre o IFMT Campus Confresa como instituição formadora de professores de ciências na região. A seção ao final do estudo apresenta as considerações finais seguida das referências utilizadas.

\section{Caracterização da Região Araguaia/Xingu}

No Nordeste do Estado de Mato Grosso, está localizada a região do Araguaia/Xingu que é composta por 14 municípios - Alto Boa Vista; Bom Jesus do Araguaia; Canabrava do Norte; Confresa; Luciara; Novo Santo Antônio; Porto Alegre do Norte; Ribeirão Cascalheira; Santa Cruz do Xingu; Santa Terezinha; São Félix do Araguaia; São José do Xingu; Serra Nova Dourada e Vila Rica (OLIVEIRA, 2016, p. 105). A região Nordeste faz parte da Bacia Hidrográfica do Araguaia (PRADO, 2010, p. 3)

Vários nomes foram atribuídos a essa região, dentre os quais predomina a nomenclatura "Araguaia/Xingu" (GARCIA, 2012, p. 8), que 
será a utilizada nesta pesquisa, mas, antes de prosseguir, nesse contexto, cabe destacar as nomenclaturas usadas para denomina-la. Garbin e Silva (2006, p. 8) a denominam como "Território do Baixo Araguaia" ou simplesmente "Baixo Araguaia". O termo "Baixo Araguaia" se dá pela localização ao final do percurso do rio [...] (OLIVEIRA, 2016, p. 103).

O site de notícias "Olhar Direto", com sede na cidade de Cuiabá, Estado de Mato Grosso, publicou uma reportagem em 25 de junho de 2012, onde a denomina como "Vale do Araguaia" (OLHAR DIRETO, 2012), está por sua vez, tornou-se a nomenclatura mais usada pelos moradores dessa região. O mesmo site, na reportagem usa o termo "Vale dos Esquecidos", para citar o descaso dos políticos (estadual e federal) para com os moradores da região. O termo "Vale dos Esquecidos" se deu em razão dos conflitos entre posseiros, grileiros, sem-terra e povos indígenas ( $\mathrm{PI}-$ NAZZA, 2015, p. 163).

\section{Procedimentos metodológicos}

O presente estudo tem características de natureza básica (GIL, 2010). Os procedimentos foram de pesquisa bibliográfica e documental, ambas assemelham-se, não sendo fácil por vezes distingui-las, no entanto a pesquisa bibliográfica utiliza fontes constituídas por material já elaborado, por livros e artigos científicos, já a pesquisa documental recorre a fontes mais diversificadas e dispersas, sem tratamento analítico, tais como: "tabelas estatísticas, jornais, revistas, relatórios, documentos oficiais, cartas, filmes, fotografias, pinturas, tapeçarias, relatórios de empresas, vídeos de programas de televisão, etc" (FONSECA, 2002, p. 32).

O diálogo com amigos e conhecidos acerca do tema pesquisado, possibilitou-nos, ter acesso a Revista Nova Escola de 1989, que abordava sobre os professores leigos da região Araguaia. Oliveira (2016), Camargo (1992), Strentzke (2011) e Albuquerque (1997) foram algumas das referências (pesquisados nos periódicos) que subsidiaram esse trabalho. Na sistematização dos resultados, usou-se o método de abordagem qualitativa.

Os pesquisadores que utilizam os métodos qualitativos buscam explicar o porquê das coisas, exprimindo o que convém ser feito, mas não quantificam os valores e as trocas simbólicas nem se submetem à prova de fatos, pois os dados analisados são não-métricos (suscitados e de interação) e se valem de diferentes abordagens (GERHARDT; SILVEIRA, 2009, p. 32). 
Nessa perspectiva e segundo Minayo (2008, p.57) o"método qualitativo é adequado aos estudos da história, das representações e crenças, das relações, das percepções e opiniões, ou seja, dos produtos das interpretações que os humanos fazem durante suas vidas, da forma como constroem seus artefatos materiais e a si mesmos, sentem e pensam".

\title{
Resultados e discussões
}

Os resultados obtidos no estudo seguem uma linha cronológica de acontecimentos, uma vez que o processo de formação dos professores de ciências da região Araguaia/Xingu ocorreu em diferentes períodos e lugares e com diferentes sujeitos. Essa linha cronológica nos permitiu estabelecer a década de 1980 como início e 2016 o fim do recorte temporal. Na introdução, fez-se um levantamento do processo histórico de formação dos professores de ciências no Brasil e, levou-se em consideração a necessidade de formação desses sujeitos.

A pesquisa evidencia ainda a formação de professores de ciências em diferentes níveis, sendo, o Magistério, Ensino Superior de currículo modular, Ensino Superior presencial, Ensino Superior a distância e Especialização.

\section{Projeto Inajá: formação oferecida aos professores leigos}

A região Araguaia/Xingu, sobremaneira, foi e é tomada por uma série de acontecimentos que marcaram inúmeros períodos da história regional, dentre os quais, se destaca a incansável luta dos "professores leigos" (STRENTZKE, 2011, p. 52) por uma formação inicial, que os permitissem exercer a profissão docente com mais "vigor".

Partindo do pressuposto "professores leigos", Tanuri (2000, p. 62), afirma que;

\begin{abstract}
Somente com a Revolução Francesa concretiza-se a ideia de uma escola normal a cargo do Estado, destinada a formar professores leigos, ideia essa que encontraria condições favoráveis no século XIX quando, paralelamente à consolidação dos Estados Nacionais e à implantação dos sistemas públicos de ensino, multiplicaram-se as escolas normais.
\end{abstract}

Segundo Scheibe (2008, p. 43), "foi no período republicano que, ao se iniciar um processo de instalação de escolas em todo o território 
nacional, foram tomadas providências mais efetivas em relação à formação dos professores". Em outras palavras, é por meio do desenvolvimento da república no Brasil que se ampliam as possibilidades de capacitação de professores para atuar na escola básica, por meio dos cursos de formação específica.

No entanto, na região Araguaia-Xingu tem sua história recente, sendo que a fundação do seu município mais antigo ocorreu em 1976, quando foi fundado São Félix do Araguaia. Nesse sentido, o processo de formação de professores nessa região se deu por volta da década de 1980. Segundo os estudos de Freitas (2002), os anos 80 representaram a ruptura com o pensamento tecnicista que predominava na região que, até então, era constituída por professores leigos, ou seja, sem formação apropriada.

O primeiro e principal programa de formação de professores que surge na região e que se têm registros foi o projeto Inajá, implantado na década de 1980. Esse projeto ofertou cursos de habilitação e formação de professores leigos para o Magistério. O projeto mesmo ocorreu em duas etapas: Inajá I (1987 a 1990) e Inajá II (1993 a 1995), com duração de três anos cada (MOREIRA; BARALDI, 2015). “O Inajá foi aprovado pelo Conselho Estadual de Educação (CEE) no parecer de número 335/88" (STRENTZKE, 2011, p. 84).

O projeto Inajá, segundo Zamboni e Rossi (1999, p. 13):

[...] foi pensado e organizado pelas lideranças locais, contou com o apoio das prefeituras e das comunidades eclesiásticas e foi desenvolvido com o apoio de professores da Unicamp de diferentes Institutos: Matemática, Física, Educação e Biologia. A parte pedagógica foi coordenada pelo Núcleo Interdisciplinar para a Melhoria do Ensino de Ciências - NIMEC, ligado à Unicamp. O projeto contou com o apoio da Secretaria de Educação do Estado de Mato Grosso, através das Coordenadorias de Educação Supletiva - CESUs, Educação para o Meio Rural e Delegacias Regionais.

O exposto mostra a necessidade de qualificação dos professores que atuavam na região Araguaia/Xingu. Nas concepções de Strentzke (2011, p. 28), “houve uma preocupação em realizar um planejamento, na perspectiva de melhorar o quadro educacional do estado, captando recursos para viabilizar projetos de capacitação e habilitação para o magistério na expectativa de habilitar professores atuantes na rede estadual de ensino". 
Ao ingressar no Inajá, exigia-se desses cursistas a idade mínima de 18 anos; exercício no magistério em escolas da rede municipal ou estadual (especialmente em classes multisseriadas da zona rural e indígena), e grau de escolaridade entre a $4^{\mathrm{a}}$ e $8^{\mathrm{a}}$ série do $1^{\circ} \mathrm{grau}$ (CAMARGO, 1992).

\begin{abstract}
A decisão de habilitar apenas professores que trabaIham em classes multisseriadas foi tomada porque eles lecionam para 4500 crianças, em locais inadequados e isolados; a própria comunidade passou a exigir a fixação deles na escola [...] a comunidade exigiu também a capacitação dos leigos para uma educação voltada para "a construção da cidadania" (SASAKI, 1989, p. 18).
\end{abstract}

O projeto "foi pautado na necessidade de uma proposta educacional que valorizasse as características locais do povo na formação de professores" (OLIVEIRA, 2016, p. 164), dentre as quais fica evidenciada a falta de formação apropriada dos professores. Assim, o projeto objetivou habilitar em nível de $2^{\circ} \mathrm{grau}$, atual Ensino Médio, aos professores rurais que trabalhavam na docência e que tinham formação apenas em nível de $1^{\circ} \mathrm{grau}$, que corresponde ao Ensino Fundamental no sistema educacional atual (SASAKI, 1989).

"Os cursistas do Inajá eram colonos, oriundos de diferentes regiões do país, culturalmente diferenciados entre si e por posseiros, moradores na região há várias gerações, outros eram índios que pertenciam as etnias Tapirapé e Karajá" (ZAMBONI; ROSSI, 1999, p. 14). Apresentamos na Figura 1 a sala de aula no período em que ocorreu o projeto Inajá.

Os cursistas precisavam se deslocar em dois momentos, pois o Inajá era organizado dessa forma. No primeiro momento (nas férias escolares em janeiro e julho), os cursistas faziam as etapas Intensivas e eram orientados por professores da Unicamp (Universidade de Campinas) e pelos Supervisores/Monitores das Secretarias Municipais de Educação. As etapas chamadas de Intermediárias (segundo momento) correspondiam aos estágios realizados durante o período letivo entre as etapas intensivas. As etapas Intensivas eram realizadas nas duas sedes do Inajá. A primeira sede localizava-se na cidade de Santa Terezinha que atendia alunos do próprio município e de Porto Alegre do Norte, a segunda sede era o município de São Félix do Araguaia que atendia o público local e de Canarana (SASAKI, 1989). 
Figura 2 - Sala de aula no tempo do projeto Inajá

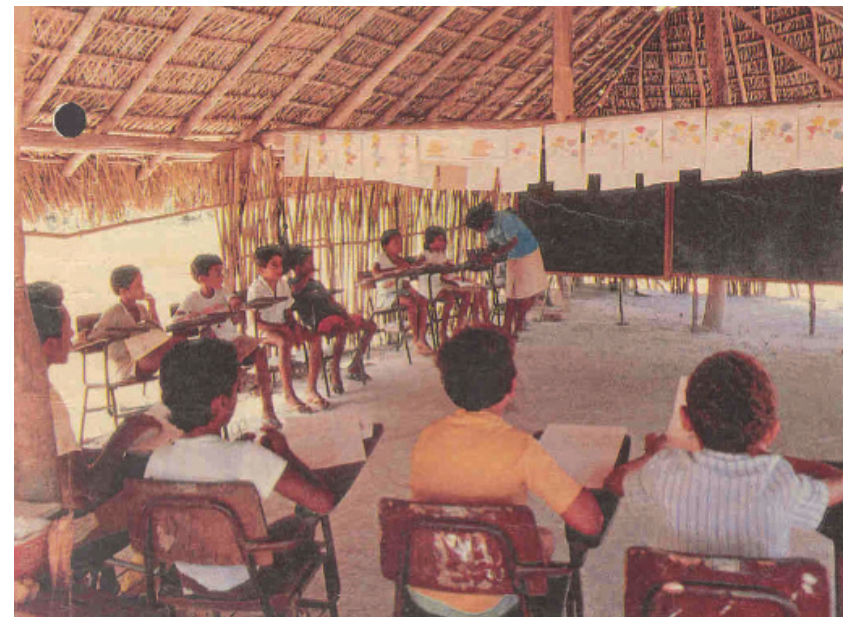

Fonte: Sasaki (1989, p. 15).

Segundo Sasaki (1989, p. 12), "as etapas intensivas eram ministradas pela equipe do Núcleo Interdisciplinar para a Melhoria do Ensino de Ciências da Unicamp". Nesse contexto o Laboratório Vivencial, foi uma das estratégias metodológicas, usadas pelos coordenadores e professores, nesse caso o observador, pode averiguar os fenômenos naturais e sociais; a prática da observação e da experimentação era a marca do projeto (ALBUQUERQUE, 1997).

A dinâmica proporcionada nas etapas Intensivas permitia que os cursistas tivessem um contato direto com o meio natural, a exemplo, temos a professora Shirlei Luz Brito (Figura 2) que ficou conhecida na época por levar uma seriema para os estudos e alimenta-la com repteis e num estudo para a classificação de animais, capturou um camaleão, cavando um formigueiro com as mãos (SASAKI, 1989).

Em relação ao ensino de ciências, a Matriz Curricular do Inajá teve apenas uma disciplina, sendo, Ciências Físicas, Ciências Biológicas e Programas da Saúde e foi ofertada em julho de 1988 com carga horária de 256 horas. A maioria dos professores que ministraram as aulas no Inajá pertencia ao quadro docente da Unicamp, destes, "Carlos A. Arguello (Unicamp) e Marcos C. D. Neves, trabalharam a disciplina de Ciências Físicas, já Adão Cardoso (Unicamp), Maria Jucinete de Souza, Maria Otacília L. Battisteli e Vicente Carichio ministraram as disciplinas de Ciências Biológicas e Programas da Saúde" (CAMARGO, 1992, p. 76). 
Figura 3 - Professora Shirlei e seus alunos

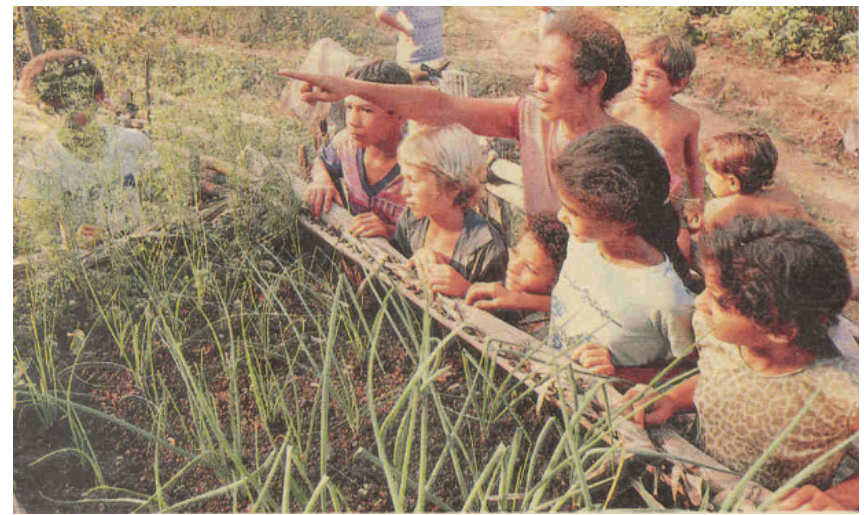

Fonte: Sasaki (1989, p. 15.

O processo formativo e a aprendizagem dos cursistas foram satisfatórios, ou seja, os cursistas conseguiram aplicar o conhecimento adquirido em suas aulas, a exemplo, temos a professora Maria de Jesus Nascimento Gama que relatou sua facilidade de fazer um plano de aula e mais segurança para trabalhar principalmente ciências e matemática. A observação científica do meio era uma das questões mais trabalhadas, ou seja, a professora Maria Ferreira Bezerra pesquisou no mês de maio a transformação da lagarta em borboleta, já Antônio Soares da Silva, observava a metamorfose da larva em mosca varejeira (SASAKI, 1989).

O Inajá representou um ponto de partida para a formação de professores na região; a avaliação do desenvolvimento do projeto a partir de suas dificuldades e possibilidades de avanço inspirou os professores que atuavam ao final da formação de $2^{\circ}$ grau a reivindicar a continuação do estudo em $3^{\circ}$ grau, originando o Projeto de Licenciatura Parcelada (OLIVEIRA, 2016).

\footnotetext{
A ideia-mãe que gerou as Parceladas não nasceu na Universidade. Surgiu como resposta a uma forte reivindicação dos concluintes do Projeto Inajá, curso de habilitação e formação de professores leigos para o Magistério ( $\left.2^{\circ} \mathrm{grau}\right)$, nos contextos rural e indígena, na região Nordeste do estado, cujo trabalho foi realizado em convênio de algumas prefeituras com a Secretaria Estadual de Educação e a Unicamp, que assumiu a coordenação pedagógica do Projeto, com base numa reflexão teórico-metodológica construtivista. (ALBUQUERQUE, 1997, p. 14).
} 
O referencial teórico usado até o momento em relação ao projeto Inajá se justifica devido ser o ponto de partida para a formação de professores na região Araguaia/Xingu, nesse sentido, em razão dos dados já apresentados e por ser uma formação em nível de magistério, acredita-se que esses professores em formação, também tiveram uma formação inicial, mesmo que de maneira generalizada, sobre as ciências naturais.

\section{Cursos de licenciatura ofertados na forma parcelada pela UNEMAT}

O início das Licenciaturas Parceladas se deu em razão da criação de um Núcleo de Apoio Educacional na cidade de Luciara no ano de 1990. Nessa época, os anseios da população foram de encontro ao processo de expansão da FESMAT (Fundação de Ensino Superior de Mato Grosso) que em 1993 passa a ser denominada de UNEMAT e o então núcleo, no ano de 1992 passa a ser um Campus. A faixada do prédio da UNEMAT pode ser visualizada na Figura 3.

Figura 4 - Prédio do Campus Universitário do Médio Araguaia em Luciara ${ }^{4}$

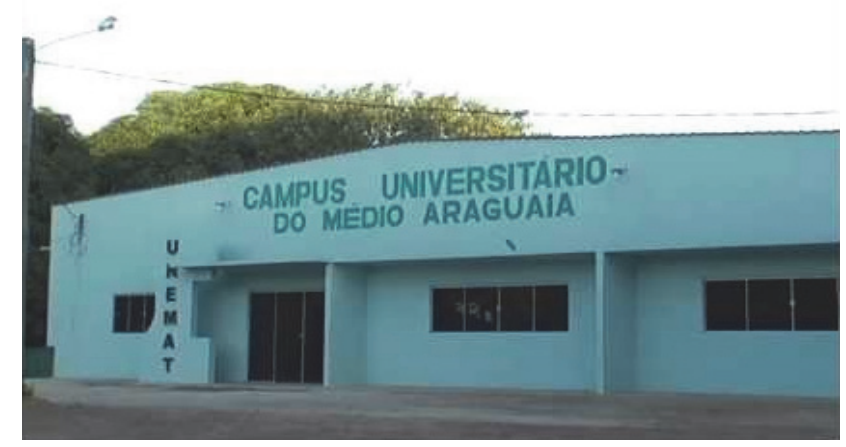

Fonte: https://i.ytimg.com/vi/fM-gOQ01hFk/hqdefault.jpg

O registro acima mostra que a implantação do Campus da então FESMAT ocorreu na cidade de Luciara, porém e por meio dos referenciais teóricos que subsidiaram este trabalho, observou-se que a cidade

4 Disponível em: https://i.ytimg.com/vi/fM-gOQ01hFk/hqdefault.jpg. Acesso em: 13 jan. 2017 
de São Félix do Araguaia seria a escolhida para este feito e em razão do descaso da prefeitura da época isso não se concretizou como mostra a reportagem do jornal Alvorada de 1992:

E a prefeitura de São Félix do Araguaia despreza a oferta e se nega a acolher esse instrumento de progresso verdadeiro, bem mais importante para todos que a luz elétrica na praia dos turistas. Ainda bem que a prefeitura de Luciara salvou, para Luciara e toda região, a Universidade de Férias. (UNIVERSIDADE..., 1992)

Moreira e Baraldi (2015) apontam que as Licenciaturas Parceladas objetivaram atender professores em serviço, portanto, trata-se de um projeto de formação em serviço e continuada em nível superior. As concepções dos autores permite-nos dizer que o público alvo das Parceladas eram os egressos do Inajá, e isso se deu por meio da UNEMAT que foi a responsável por ofertar as Licenciaturas Parceladas na região Araguaia/Xingu.

\footnotetext{
Os cursos Parceladas tentou seguir o formato do projeto Inajá e eram ofertados no período de férias, tinham a vantagem tanto para os alunos, quanto para a universidade, pois, os alunos continuariam atuando como professores, e tendo sua formação superior e a instituição atingiria vários municípios em um só polo (MOREIRA; BARALDI, 2015, p. 10).
}

O Campus Universitário do Médio Araguaia na cidade de Luciara, Estado de Mato Grosso, tornou-se a grande conquista para a população da região Araguaia/Xingu e em especial para os professores que até então eram chamados de leigos. A oferta de cursos no formato das Licenciaturas Parceladas possibilitou primeiramente a qualificação de professores na região e, depois a formação dos jovens que saiam do $2^{\circ}$ grau. Assim poderiam ter perspectivas de continuidade e não migrariam para outras regiões (OLIVEIRA, 2016).

O Projeto original do Programa Parceladas planejou cursos de licenciaturas plenas na modalidade diferenciada, contemplando as características da região e do Estado, com efetivação da proposta teórica/metodológica solicitada; foram oferecidas no início apenas três cursos de licenciatura: Matemática, Letras e Pedagogia, 
os quais eram considerados emergenciais para atender a demanda da região, tanto na rede pública de ensino estadual quanto municipal (ALMEIDA; PIMENTA, 2014, p. 130).

A aceitação pelas Licenciaturas Parceladas permitiu a oferta de novos cursos, bem como a expansão do Campus Universitário do Médio Araguaia. Em relação à oferta de novos cursos, Almeida e Pimenta (2014, p. 131) relatam que "após a finalização dos três primeiros cursos de licenciatura, foram oferecidos mais três cursos: História, Biologia e Geografia". Nessa época o processo de formação dos professores de ciências se concretiza na região Araguaia/Xingu, pois surge o primeiro curso superior (Biologia) voltado para essa finalidade.

Nos apontamentos de Oliveira (2016, p. 192) "a proposta curricular do curso não seria construída de imediato, mas ao longo do tempo, diante das experiências e vivências dos professores, monitores e alunos". O processo formativo de professores de ciências na região Araguaia/Xingu se concretizou com a oferta do primeiro curso de Biologia, porém os futuros professores de ciências, em sua maioria de classe média, apresentaram ter uma trajetória de mais de 15 anos de escolarização formal (CASSIANI; VON LINSINGEN, 2009).

O Edital n. ${ }^{\circ}$ 001/2006 - UNEMAT possibilitou a abertura do seletivo para as Licenciaturas Plenas Parceladas e dentre os cursos a serem ofertados, estava a Licenciatura Plena em Ciências Biológicas que visava à formação de profissionais para realizar atividade docente nas diversas áreas da Biologia. O edital ressalta ainda que o Curso de Licenciatura Plena em Ciências Biológicas, ofertado pelo Projeto de Licenciaturas Plenas Parceladas, por meio da Divisão de Licenciaturas Parceladas - UNEMAT visa à formação de professores de Ciências (Ensino Fundamental) e de Biologia (Ensino Médio) com competências e habilidades educativas e científicas na área das Ciências Biológicas e na área da Educação.

O Brasil necessita de 235 mil professores para o Ensino Médio, a exemplo, o déficit apresentado para a disciplina de Física é de $9 \%$ e para a disciplina de Química chega aos 13\%. No ano de 2007 são tomadas várias medidas para minimizar essa problemática (SOUSA; BERALDO, 2009). Desse modo, a oferta do curso de Química no ano de 2007 no Campus de Luciara (ALMEIDA; PIMENTA, 2014) reforça o processo formativo dos professores para atuarem nessa área de conhecimento. 
Adotando uma estrutura multicampi para responder às crescentes demandas do interior do Estado por qualificação de professores, a UNEMAT, num gesto de ousadia, se propôs realizar o Projeto de Licenciaturas Plenas Parceladas, na tentativa de responder adequadamente às urgentes necessidades da formação de professores em exercício no Ensino Fundamental e Médio. (ALBUQUERQUE, 1997, p. 14).

A estrutura multicampi da UNEMAT possibilitou ainda a criação de dois Núcleos Pedagógicos, um na cidade de Confresa e o segundo no município de Vila Rica distante 100 km um do outro. Os Núcleos Pedagógicos têm ofertado principalmente cursos de graduação (Letras/Inglês, Ciências Sociais, Educação Física e Ciências da Computação) voltados à formação de professores. A dinâmica de oferta desses cursos continua sendo por meio do programa Parceladas e também na modalidade "regular", ou seja, os acadêmicos estudam todos os dias.

A continuidade da oferta de cursos voltados à formação de professores em ciências e das demais disciplinas mostra que a UNEMAT tem agido para que esse déficit, bem como a falta de profissionais habilitados diminua e dessa forma melhore o processo de ensino e aprendizagem na região Araguaia/Xingu.

\section{Compromisso do IFMT no atendimento das demandas locais}

Outro marco importante para a formação de professores em ciências na região Araguaia/Xingu foi à implantação de um Campus do Instituto Federal de Educação, Ciência e Tecnologia de Mato Grosso (IFMT) na Cidade de Confresa. A estrutura atual do Campus pode ser observada na Figura 5.

Para Sousa e Beraldo (2009) a expansão dos CEFETs e a consequente transformação destas instituições em Institutos Federais de Educação, Ciência e Tecnologia está relacionada com a política do governo federal para a formação de professores, em especial para as disciplinas de Física, Química, Biologia e Matemática. Tal política foi instituída pelo Decreto № 6.755 de 29 de janeiro de 2009 e visa formar, nos próximos cinco anos, 330 mil professores que atuam na educação básica e ainda não são graduados.

Inaugurado em fevereiro de 2010, o campus Confresa já iniciou o trabalho pedagógico com a oferta dos se- 
guintes cursos: Licenciatura em Ciências da Natureza - habilitação em Química, Licenciatura em Ciências Agrícolas e Bacharelado em agronomia [...] (SILVA, 2013, p. 7/8).

Figura 5 - IFMT Campus Confresa

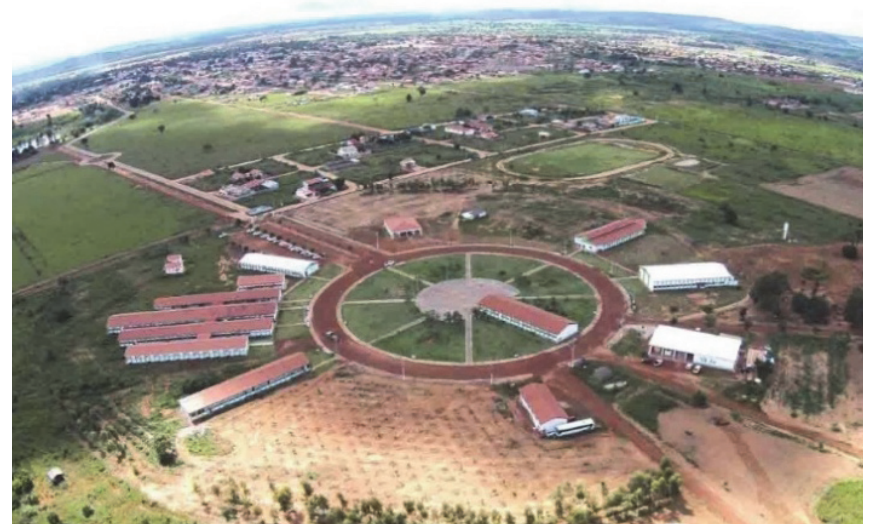

Fonte: https://i.ytimg.com/vi/fM-gOQ01hFk/hqdefault.jpg

Para atender a legislação vigente e uma demanda da região Araguaia/Xingu o Campus Confresa em 2010 passa a ofertar a Licenciatura em Ciências da Natureza com Habilitação em Química, tal Licenciatura, "[...] deu-se por meio de audiências públicas" (DUTRA; BAMPI, 2015, p. 126). Nestas audiências públicas, constatou-se que eram poucos os profissionais habilitados nessa especificidade e que atuavam em sala de aula. Nesse sentido, o Campus "[...] possui um perfil agrícola, e seu principal ofício é formar profissionais que atuarão nas áreas de produção animal, vegetal e agroindustrial e na formação de professores" (DUTRA; BAMPI, 2015, p. 126).

A Licenciatura em Ciências da Natureza com Habilitação em Química em seu Projeto Pedagógico de Curso possui uma carga horária total de 3200 horas divididas em quatro anos. "O regime é anual e o curso respeita os pareceres e resoluções do Conselho Nacional de Educação e também está estruturado de acordo com as normas do Conselho Fe-

5 Disponível em: https://i.ytimg.com/vi/SjzjfzA2uZk/maxresdefault.jpg. Acesso em: 8 jan. 2017. 
deral de Química e do Conselho Regional de Química de Mato Grosso" (JESUS; GARCÊS, 2013, s/p).

Os autores (idem) ressaltam também que o curso apresenta formação teórico-prática e metodológica, construindo conhecimentos e valorizando a pesquisa e extensão, especialmente as de base multidisciplinar, como instrumentos de consolidação do aprendizado e transformação individual e coletiva. Em sua Matriz Curricular, o discente irá cursar disciplinas de formação instrumental, formação pedagógica, formação específica em ciências e formação específica em química.

A construção desse conhecimento acontece desde o início do curso, ou seja, o Campus Confresa, proporciona aos acadêmicos, atividades e ações que fazem os acadêmicos se sentirem sujeitos do seu próprio processo de formação, a exemplo, os acadêmicos do Campus, têm a oportunidade de participar de inúmeros eventos científicos a nível regional (Feiras de Ciências, Fóruns de Educação) e nacional (Congresso Brasileiro de Química, SemiEdu, WorkIF).

A participação nesses eventos tornou-se um incentivo para que os acadêmicos escrevam e produzam relatos de experiências, resumos expandidos e até mesmo artigos científicos. A participação dos acadêmicos de química nas edições do Congresso Brasileiro de Química tem sido uma tradição do Campus e acontece desde 2010.

Além dessas ações de incentivo, a construção do conhecimento do professor de ciências na região Araguaia/Xingu se dá com as aulas experimentais durante o processo de formação. As aulas experimentais tem sido uma exigência para o reconhecimento dos cursos de química, biologia e física e surge como uma necessidade desse sujeito em assimilar a teoria e pratica e de igual forma aplica-la no exercício da profissão, ou seja, em sala de aula. As aulas experimentais no Campus Confresa seguem todas as normais e padrões mínimos (exigidos) de segurança em um laboratório.

Ao concluir o seu processo formativo, o professor de ciências, na região Araguaia/Xingu enfrentara dificuldades para trabalhar e também aplicar no processo de ensino e aprendizagem de seus alunos as aulas experimentais que outrora aprendera. Essa dificuldade tem sido a nossa realidade.

A dificuldade apresentada é decorrente da falta de estrutura das escolas da região Araguaia/Xingu, ou seja, percebeu-se que quase $100 \%$ (cem por cento) das escolas não têm ou possuem espaços (laboratórios de ciências) adequados para que se desenvolva uma aula experimental. 
O professor de ciências, formado no Campus Confresa, terá condições de minimizar essa dificuldade, pois, além das aulas experimentais que acontecem nos laboratórios, usam-se estratégias de desenvolvimento das mesmas com materiais alternativos, desse modo, na região Araguaia/Xingu, o ensino de ciências com materiais alternativos está sendo desbravado.

\section{O atendimento das demandas locais via educação a distância}

Segundo Almeida (2002), a educação a distância, desde o século XIX, foi usada para tornar a educação convencional acessível às pessoas residentes em áreas isoladas ou àqueles que não tinham condições de cursar o ensino regular no período apropriado, o que lhe deu a reputação de educação de baixo custo e de segunda classe.

No Brasil, a Educação a Distância (EAD) foi popularizada e vem sendo usada para suprir a necessidade de formação em várias Instituições de Ensino Superior (IES), nesse sentido, Araújo e Freitas (2005), ressaltam que nesse nível de ensino, tem-se um número cada vez maior de estudantes, professores e instituições, tanto públicas como privadas, em um novo conjunto de desafios.

Partindo desse pressuposto, o IFMT via Universidade Aberta do Brasil (UAB) tem ofertado cursos na modalidade da educação a distância, nesse sentido a Portaria do MEC n॰ 251 de 31/05/2013, regulamenta e autoriza a oferta do curso Licenciatura em Química na cidade de Ribeirão Cascalheira, a oferta do curso, reforça a formação de professores de ciências na região Araguaia/Xingu.

\section{O atendimento das demandas locais via formação continuada}

A verticalização de estudos no Campus é possível e os interessados podem dar sequência por meio da Especialização em Ensino de Ciências. O propósito principal é oferecer um curso de formação continuada que atenda alunos egressos dos cursos de Licenciatura em Ciências da Natureza e profissionais da rede pública de ensino.

Ofertando cursos de graduação e, principalmente, de pós-graduação, a instituição aprimorará a tripartite da educação: Ensino, Pesquisa e Extensão, uma vez que o projeto integrará as diferentes redes em um 
único projeto de formação educacional, promovendo, assim, o desenvolvimento de pesquisas e projetos relacionados ao Ensino de Ciências (EICKHOFF et al., 2014, p. 11).

Segundo Oliveira, Alves e Leão (2016), o IFMT Campus Confresa vem contribuindo significativamente para a formação de professores de ciências naturais na região, pois, desde 2010 tem ofertado qualificação profissional a inúmeras pessoas, habilitando-os em Ciências da Natureza - Habilitação em Química e a partir de 2015 com os dois novos cursos de licenciatura citados anteriormente. Todas essas ações objetivam suprir a necessidade de capacitar professores de ciências naturais, pois ainda carece desses profissionais habilitados na região.

O Campus Confresa, além da formação inicial em ciências, tem contribuído com a formação continuada desses profissionais. A continuidade de estudos referente ao ensino de ciências no Campus é possível,

\begin{abstract}
o curso de pós-graduação lato sensu em Ensino de Ciências tem por objetivo oferecer aos professores do Ensino Fundamental e Médio, capacitação em nível de especialização, na área de Ensino de Ciências (Biologia, Física, Química), de forma a torná-los promotores de mudanças no cenário atual das escolas em que estão inseridos, buscando assim maior qualidade na educação de seus alunos e melhor formação para o exercício da cidadania (EICKHOFF et al., 2014, p. 11).
\end{abstract}

A formação inicial e continuada ofertada pelo IFMT Campus Confresa para capacitar professores de ciências naturais na região Araguaia-Xingu vem reafirmar o compromisso dos Institutos Federais com a oferta formativa em benefício da consolidação e fortalecimento local. O próprio artigo $7^{\circ}$ da Lei 11.892 (BRASIL, 2008), afirma que é objetivo da instituição ofertar cursos de licenciatura, bem como programas especiais de formação pedagógica, com vistas na formação de professores para a educação básica, sobretudo nas áreas de ciências e matemática.

Essa formação pedagógica, no Campus Confresa se dá de várias formas, ou seja, a construção desse conhecimento é contínua e na Especialização em Ensino de Ciências foi especifica e teve enfoque no processo de ensino e aprendizagem em ciências, ou seja, os pós-graduandos desde o início do curso começaram a discutir e traçar estratégias e metodologias para melhorar o ensino de ciências nas escolas em que atuavam. 
Assim como na formação inicial, a construção do conhecimento dos pós-graduandos se deu pela produção de vários materiais. Incentivados a participar de vários eventos (WorkIF, SemiEdu, Congresso Brasileiro de Química), os pós-graduandos produziram resumos expandidos, relatos de experiências e artigos científicos e também foram autores de capítulos de livros que abordam o ensino de ciências.

\section{Considerações Finais}

A região Araguaia/Xingu sempre foi marcada pelas lutas por posses de terra, além dos conflitos étnicos que também se estabeleceram ao longo dos anos. Como se não bastasse, a região também sofreu com o descaso no que tange a formação de professores, em especial a de professores de ciências naturais. Pelos registros encontrados nesse estudo, somente na década de 80 é que houve iniciativas para qualificar os profissionais que atuavam em sala de aula. Se formos comparar com o sudeste e sul do país, que possuem um histórico de oferta de cursos oficiais de capacitação na área é um atraso de quase 50 anos, porém é preciso lembrar que essa região foi povoada por não-indígenas somente na decana de 70 do século passado.

O projeto Inajá possibilitou formação complementar aos professores e professoras leigas, cujo objetivo foi dar o embasamento mínimo para ministrarem suas aulas. Esse foi o primeiro passo, porém as lutas continuaram no sentido de que houvesse a oferta de formação de professores de ciências naturais em nível de Graduação e de Pós-Graduação.

Nesse sentido, as licenciaturas parceladas da UNEMAT e os cursos de licenciatura e pós-graduação na área de ciências naturais ofertados pelo IFMT Campus Confresa, confirmam o compromisso dessas Instituições de Ensino Superior (IES) com o desenvolvimento da Região Araguaia/Xingu. Essa preocupação em atender as demandas de qualificação na região, por meio de cursos de graduação e pós-graduação, mostra que avanços houve e que formar profissionais habilitados na área específica de conhecimento pode favorecer significativamente o ensino e a aprendizagem de ciências naturais nas escolas da região.

Espera-se que o estudo contribua como registro para o processo formativo de professores de ciências naturais, pois as dificuldades em relação à oferta, ao acesso e a permanência na formação específica são 
superadas quando a sociedade age de forma organizada e atenta às suas necessidades.

Precisamos avançar ainda mais quanto às políticas públicas que visam interiorizar a educação superior no Brasil, mas os primeiros passos já foram dados, prova disso é o que aconteceu aqui na região Araguaia/ Xingu. Logo, não podemos ficar apenas com as licenciaturas e a especialização em Ensino de Ciências aqui relatadas, as próximas conquistas necessárias para a formação de formação de ciências naturais é a oferta da Pós-graduação Stricto Sensu no nível de Mestrado e Doutorado, que será um marco histórico para a região.

\section{Referências}

ALBUQUERQUE, J. G. de. Uma Proposta de Integração Entre Ensino e esquisa. Adusp. São Paulo, v. x, n. 10, p.15-23, jun. 1997. Disponível em: http:// www.adusp.org.br/files/revistas/10/r10a02.pdf. Acesso em: 9 jan. 2017.

ALMEIDA, M. E. B. de. A educação à distância no Brasil: diretrizes políticas, fundamentos e práticas. In: Actas do VI Congresso Iberoamericano de Informática Educativa,Vigo: RIBIE, nov. 2002. 6 p. Disponível em: http://www.igm.mat.br/profweb/sala_de_aula/mat_ computacional/2006_2/artigos/artigo2.pdf. Acesso em: 1 jun. 2017.

ALMEIDA, V. H. de; PIMENTA, A. C. Um Estudo Sobre as Tendências da Educação Matemática nos Cursos de Licenciatura em Matemática do Programa Parcelada nos Últimos 10 Anos. In: SEMANA DE LICENCIATURA, 2014, Jatai. Anais ... Jatai, 11., 2014. p. 127 - 138. Disponível em: http:// www.ifg.edu.br/jatai/semlic/seer/index.php/anais/article/view/328/ pdf_109. Acesso em: 12 jan. 2017.

ARAUJO, B.; FREITAS, K. S. de. Educação a Distância no contexto brasileiro: algumas experiências da UFBA. Salvador: ISP/UFBA, 2005. 170 p. Disponível em: http://www.proged.ufba.br/ead/EADnaUFBA.pdf. Acesso em: 1 jun. 2017.

AYRES, A. C. M.; SELLES, S. E. História da Formação de Professores: Diálogos com a Disciplina Escolar Ciências no Ensino Fundamental. Ensaio. Belo Horizonte, v. 14, n. 2, p.95-107, maio/ago. 2012.

BAROLLI, E.; VILLANI, A. A formação de professores de ciências no brasil como campo de disputas. Exitus. Santarém, v. 5, n. 1, p.72-90, jan./jun. 2015. 
BRASIL. Lei no 11892, de 29 de dezembro de 2008. Institui a Rede Federal de Educação Profissional, Científica e Tecnológica, Cria os Institutos Federais de Educação, Ciência e Tecnologia, e dá Outras Providências. Diário Oficial [da] República Federativa do Brasil, Brasília, DF, 30 dez. 2008. Disponível em: http://www.planalto.gov.br/ccivil_03/_ato20072010/2008/lei/l11892.htm. Acesso em: 16 abr. 2017.

CAMARGO, D. M. P. de. Mundos Entrecruzados. Projeto Inajá: uma experiência com professores leigos no Médio Araguaia-MT (1987 - 1990). 1992. 301f. Tese de Doutorado (Doutorado em Educação). Faculdade de Educação, Universidade Estadual de Campinas, Campinas, 1992

CARVALHO, A. M. P. de; GIL-PÉREZ, D. Formação de professores de ciências: tendências e inovações. 2. ed. São Paulo: Cortez, 1995. 120p.

CARVALHO, A. M. P. de; GIL-PÉREZ, D. O saber e o saber fazer do professor. In: CASTRO, Amélia D.; CARVALHO, Anna Maria P. (Org.). Ensinar a ensinar: didática para a escola fundamental e média. São Paulo: Pioneira Thomson Learning, 2001. p. 107-124.

CASSIANI, S.; VON LINSINGEN, I. Formação inicial de professores de Ciências: perspectiva discursiva na educação CTS. Educar. Curitiba, n. 34, p.127-147. 2009. Disponível em: http://www.scielo.br/pdf/er/n34/08. pdf. Acesso em: 13 jan. 2017.

DUTRA, M. M.; BAMPI, A. C. Práticas Docentes, Formação em Agronomia, Agricultura Familiar e Sustentabilidade no Contexto do Baixo Araguaia, Mato Grosso, Brasil. Educação, Cultura e Sociedade. Sinop, v. 5, n. 1, p.123-145, jun. 2015.

EICKHOFF,A.P.doN.etal.ProjetoPedagógicodeCursodePós-Graduação Lato Sensu: Especialização em Ensino de Ciências. 2014. Disponível em: http://cfs.ifmt.edu.br/media/filer_public/86/59/86590d05-a42c-4117afd8-de7aed8afb2c/ppc_especializacao_em_ensino_de_ciencias.pdf. Acesso em: 5 mar. 2017.

FONSECA, J. J. S. Metodologia da pesquisa científica. Fortaleza: UEC, 2002. Apostila.

FREITAS, D. de; VILLANI, A. Formação de professores de ciências: um desafio sem limites. Investigações em Ensino de Ciências. v. 7, n. 3, p. 215-230, 2002. 
FREITAS, H.C.L. de. Formação de Professores no Brasil: 10 Anos de Embate Entre Projetos de Formação. Educ. Soc. Campinas, v. 23, n. 80, p.136-167, set. 2002. Disponível em: http://www.scielo.br/pdf/es/v23n80/12928. pdf. Acesso em: 8 jan. 2017.

GARBIN, V. H.; SILVA, M. J. Plano Territorial de Desenvolvimento Rural Sustentável: Território Baixo Araguaia - MT. 2006. Disponível em: http:// sit.mda.gov.br/download/ptdrs/ptdrs_territorio019.pdf. Acesso em: 07 jan. 2017.

GARCIA P. C. Realidade e História da Região do Araguaia Xingu. Carlos Garcia Paret. São Paulo: Instituto Sociambiental, 2012. - (Serie A resposta da terra: v. 2). Disponível em: http://axa.org.br/publicacoes/realidade-ehistoria-da-regiao-do-araguaia-xingu/. Acesso em: 8 jan. 2017.

GERHARDT, T. E.; SILVEIRA, D. T. (Org.). Métodos de pesquisa. Porto Alegre: Ed. da UFRGS, 2009.

GIL, A. C. Métodos e Técnicas de Pesquisa Social. 6 ed. São Paulo: Atlas 2010.

JESUS, E. B.; GARCÊS, B. P. Análise da Matriz Curricular do Curso de Licenciatura em Ciências da Natureza com Habilitação em Química do Instituto Federal de Mato Grosso - Campus Confresa. In: CONGRESSO BRASILEIRO DE QUÍMICA, 53., 2013, Rio de Janeiro. Anais... Rio de Janeiro: $A B Q, 2013$. Disponível em: http://www.abq.org.br/cbq/2013/ trabalhos/13/2297-14213.html. Acesso em: 12 jan. 2017.

MALUCELLI, V. M. B. Formação dos Professores de Ciências e Biologia: reflexões sobre os conhecimentos necessários a uma prática de qualidade. Estud. Biol. Curitiba, v. 1, n. 1, p.113-116, jan./mar. 2007.

MINAYO, M. C. S. $O$ desafio do conhecimento. 11 ed. São Paulo: Hucitec, 2008.

MOREIRA, W. B.; BARALDI, I. M. Algumas Percepções Históricas sobre a Formação de Professores de Matemática no Baixo Araguaia. In: SIMPÓSIO INTERNACIONAL DE LINGUAGENS EDUCATIVAS, 5. ed., 2015, Bauru. Anais [...] Bauru: Atual, 2015. v. 1, p. 1 - 5. Disponível em: https:// www.usc.br/custom/2008/uploads/wp-content/uploads/2015/05/ Algumas-Percep\%C3\%A7\%C3\%B5es-Hist\%C3\%B3ricas-sobre-aForma\%C3\%A7\%C3\%A3o-de-Professores-de-Matem\%C3\%A1 tica-noBaixo-Araguaia.pdf. Acesso em: 10 jan. 2016. 
MOURA, R. M. T. de. Professores de Ciências em Ação: uma Perspectiva de Formação Docente. 2006. 198 f. Dissertação (Mestrado em Educação) - Universidade Estadual do Ceará, Fortaleza, 2006. Disponível em: http://www.uece.br/ppge/dmdocuments/'Dissertacao Marconcio.pdf. Acesso em: 02 mar. 2017.

OLHAR DIRETO. Conflito expõe porquê Araguaia se tornou “Vale dos Esquecidos" em MT. 2012. Disponível em: http://www.olhardireto.com. br/noticias/exibir.asp?id=264483. Acesso em: 08 jan. 2016.

OLIVEIRA, D. F. L.; ALVES, A.C.T.; LEAO, M. F. O Processo de Formação dos Professores de Ciências da Região Araguaia/Xingu. In: MOSTRA DOS CURSOS DE ESPECIALIZAÇÃO DO IFMT, 1, 2016, Confresa. Anais... Confresa: IFMT, 2016. p. 117-121.

OLIVEIRA, M. R. A. A Educação e a Luta no Araguaia (Mato Grosso). 2016. $240 \mathrm{f}$. Tese (Doutorado em Geografia Humana) - Faculdade de Filosofia, Letras e Ciências Humanas, Universidade de São Paulo, São Paulo, 2016.

PINAZZA, N. Esquecer de lembrar. Significação. São Paulo, v. 42, n. 44, p.160-174, nov. 2015. Disponível em: http://www.revistas.usp.br/ significacao/article/viewFile/103325/106901. Acesso em: 08 jan. 2017.

PRADO, R. C. O. et al. Instituto Matogrossense de Economia Agropecuária: Mapa de Macrorregiões do IMEA. Cuiabá, 2010. 6 p. Disponível em: http://www.imea.com.br/upload/publicacoes/arquivos/ justificativamapa.pdf. Acesso em: 8 jan. 2017.

SASAKI, R. Araguaia: Leigos conquistam uma nova formação e adaptam o ensino a realidade local. Nova Escola. São Paulo, v. 32, n. 4, p.12-19, ago. 1989.

SCHEIBE, L. Formação de professores no Brasil: a herança histórica. Retratos da Escola. Brasilia, v. 2, n. 2-3, p.41-53, dez. 2008. Disponível em: http://www.cnte.org.br/images/stories/2012/revista_retratosda escola_02_03_2008_formacao_professores.pdf. Acesso em: 25 jul. 2016.

SILVA, A. F. da. O político e o pedagógico: análise das enunciações dos docentes e dos discentes do curso Técnico em Agropecuária. 2013. 60f. Dissertação (Mestrado em Educação. Agrícola) - Instituto de Agronomia, Universidade Federal Rural do Rio de Janeiro, Seropédica-RJ, 2013. 
SOUSA, A. G. BERALDO, T. M. Cursos de Licenciatura em Ciências Naturais nos Institutos Federais de Educação, Ciência e Tecnologia. In: CONGRESSO NACIONALDEEDUCAÇÃO. 9.2009, Curitiba. Anais...Curitiba:Champagnat, 2009. p. 10169 - 10182. Disponível em: http://www.pucpr.br/eventos/ educere/educere2009/anais/pdf/1920_1102.pdf. Acesso em: 13 jan. 2017. STRENTZKE, I. Inajá, homem-natureza, geração tucum: Uma análise da proposta. Pedagógica de 1987 a 2000. 2011. 128 f. Dissertação (Mestrado em Educação) - Universidade. Federal de Mato Grosso, Cuiabá-MT, 2011. TANURI, L. M. História da formação de professores. Revista Brasileira de Educação. São Paulo, s/v, n. 14, n. x, p.61-88, maio/ago. 2000. Disponível em: http://www.scielo.br/pdf/rbedu/n14/n14a05. Acesso em: 13 ago. 2016.

UNIVERSIDADE de férias. Alvorada. São Félix do Araguaia, jan/fev. 1992. ZAMBONI, E.; ROSSI, V. L. S. de. A formação de professores leigos nas áreas das fronteiras agrícolas do Brasil Central. Perspectiva. Florianópolis, v. 17, n. x, p.13-31, jun. 1999.

Recebido em: maio/2018

Aprovado em: agosto/2018 